\title{
STIRILLAKTON TERASETILISASI DARI DAUN TENDANI (Goniothalamus macrophyllus Hook.f. \& Thoms) ASAL KALIMANTAN TIMUR
}

\author{
Agung Rahmadani \\ Laboratorium Penelitian dan Pengembangan Farmaka Tropis \\ Fakultas Farmasi Universitas Mulawarman \\ email : agung@farmasi.unmul.ac.id
}

\begin{abstract}
ABSTRAK
Senyawa turunan stirillakton terasetilisasi telah berhasil diisolasi dari daun tendani (Goniothalamus macrophyllus Hook.f. \& Thoms) asal Kalimantan Timur. Isolasi dimulai dengan maserasi menggunakan metanol, kemudian difraksinasi dengan n-heksana dan etil asetat. Ekstrak etil asetat diisolasi dengan teknik kromatografi kolom. Struktur isolat ditentukan strukturnya berdasarkan Spektroskopi Massa (MS), NMR (1D dan 2D). Struktur turunan stirillakton yang berhasil diisolasi diketahui sebagai 9-deoksigoniopipiron asetat.
\end{abstract}

Kata Kunci: Daun tendani, goniothalamus macrophyllus, stirillakton, 9deoksigoniopipiron asetat

\section{PENDAHULUAN}

Genus

Goniothalamus

(Annonaceae) terdiri dari 130 spesies, kebanyakan tersebar sepanjang negara tropis dan subtropis [1]. Salah satu spesies dari genus ini ialah tumbuhan tendani (Goniothalamus macrophyllus Hook.f. \& Thoms. Tumbuhan ini hidup di daerah hutan dan lahan perdu, dapat tumbuh baik di tanah agak basah dan mampu tumbuh pada musim hujan serta kemarau. Tumbuhan tendani diketahui tumbuh di daerah Semenanjung Malaysia, Thailand dan Kalimantan [2]. Masyarakat Thailand, Malaysia, dan Kalimantan sering menggunakan tumbuhan ini sebagai obat.

Kelompok metabolit sekunder yang telah berhasil diisolasi dari Goniothalamus macrophyllus Hook.f. \& Thoms yaitu kelompok stirillakton, flavonoid, dan alkaloid. Stirillakton merupakan metabolit utama dari spesies ini seperti goniothalamin dan goniothalamin oksida yang telah diisolasi dari kulit batang kayu Goniothalamus macrophyllus Hook.f. \& Thoms dan bersifat embriotoksik dan teratogenik [3]. Pada bagian akarnya, berhasil diisolasi senyawa yang bersifat sitotoksik yaitu goniodiol, 8-metoksi goniodiol, goniolandren A dan B [4]. Senyawa flavonoid yang berhasil diisolasi dari tumbuhan ini ialah pinocembrin [2] dan linderaton [4]. Sedangkan senyawa alkaloid yang berhasil diisolasi ialah markanin, dielskuinon dan liriodenin [2]. Tumbuhan ini juga mengandung minyak atsiri dan telah teridentifikasi diantaranya a-pinena, linalool dan geraniol yang bersifat sebagai antimikroba [5]. Secara umum ada 4 golongan metabolit sekunder yang terdapat pada genus Annonaceae diantaranya asetogenin, stirillakton, alkaloid dan flavonoid [4].

\section{METODE}

\section{ALAT DAN BAHAN \\ Alat yang digunakan pada penelitian ini yaitu seperangkat alat gelas,}


kolom kromatografi, rotary evaporator, UV 254 dan $366 \mathrm{~nm}$, NMR JEOL JNMECA $500 \mathrm{MHz}$, dan MS QP2010S Shimadzu. Bahan penelitian ini yaitu silika gel GF 60, metanol, n-heksana, etil asetat, kloroform, plat KLT.

\section{EKSTRAKSI DAN ISOLASI}

Sampel penelitian yaitu daun tendani (Goniothalamus macrophyllus Hook.f. \& Thoms) yang diambil dari hutan di kecamatan Babulu darat, Kabupaten Penajam Paser Utara, Kalimantan Timur. Ekstraksi dilakukan dengan metode maserasi menggunakan pelarut metanol. Sebanyak $1 \mathrm{~kg}$ daun tendani kering dimaserasi dengan metanol selama 3 hari. Maserat dipekatkan dengan menggunakan rotary evaporator pada suhu $40^{\circ} \mathrm{C}$. Ekstrak kasar metanol difraksinasi dengan n-heksana : air (1:1), kemudian residunya difraksinasi kembali dengan etil asetat. Sehingga didapatkan ekstrak etil asetat dengan berat 3,8 g.

Ekstrak etil asetat diisolasi dengan menggunakan kromatografi kolom. Sampel dielusi secara bertingkat kepolarannya dengan eluen n-heksana : etil asetat $(9: 1 ; 8,5: 1,5 ; 7: 3 ; 6: 4 ; 1: 1)$. Kromatografi kolom ekstrak etil asetat menghasilkan 7 fraksi. Fraksi 4 (302 mg) dikromatografi kolom ulang dengan eluen n-heksana : etil asetat (8:2) menghasilkan 5 isolat fraksi. Fraksi 4.1 (46 mg), 4.2 (78 $\mathrm{mg}), 4.3$ (9 mg), 4.4 (44 mg), 4.5(116 mg). Fraksi 4.3 berbentuk kristal jarum bening dan dielusidasi strukturnya.

\section{PENENTUAN STRUKTUR}

Struktur isolat fraksi 4.3 ditetapkan berdasarkan hasil analisis data spektroskopi, yang meliputi spektroskopi massa (MS) dan NMR $\left({ }^{1} \mathrm{H}-\mathrm{NMR},{ }^{13} \mathrm{C}-\right.$ NMR, COSY, HMQC, dan HMBC). Spektra massa menggunakan metode EIMS dan spektrum NMR diukur dalam pelarut $\mathrm{CDCl}_{3}$

\section{HASIL DAN DISKUSI}

Daun tendani diekstraksi menggunakan metode maserasi. Selama maserasi, metanol akan menembus dinding sel dan masuk ke rongga sel yang mengandung senyawa aktif di dalam sel, sehingga senyawa yang diinginkan akan terdesak keluar sel. Proses ini disebabkan perbedaan tekanan antara di dalam dan luar sel sehingga metabolit sekunder yang ada di dalam sitoplasma akan terlarut dalam pelarut. Dengan mengalirnya pelarut ke dalam sel dapat menyebabkan protoplasma membengkak dan senyawa dalam sel akan terlarut sesuai dengan kelarutannya dan berpindah secara osmosis melalui rongga antar sel.

Fraksinasi dilakukan untuk mempersempit keberadaan senyawa yang akan diisolasi. Fraksinasi mengelompokkan senyawa berdasarkan kesamaan sifat fisik terhadap pelarut yang digunakan. Fraksinasi yang biasa digunakan ialah fraksinasi cair-cair. Senyawa-senyawa non polar akan terdistribusi ke pelarut n-heksana, selain itu juga pelarut ini akan menarik klorofil yang banyak berada di daun sehingga nantinya klorofil tidak mengganggu pada saat isolasi.

Senyawa yang berhasil diisolasi dari daun tendani (Goniothalamus macrophyllus Hook.f. \& Thoms) dengan menggunakan kromatografi kolom yaitu 9-deoksigoniopipiron asetat berbentuk kristal jarum bening. Spektra massa menunjukkan m/z 276 sebagai massa molekul 9-deoksigoniopipiron asetat. Fragmentasi massa dengan $\mathrm{m} / \mathrm{z} 43$ dengan kelimpahan $100 \%$ menunjukkan bahwa struktur memiliki gugus asetil

9-deoksigoniopipiron asetat, ${ }^{1} \mathbf{H}-N M R(\mathbf{C D C l} \mathbf{3}, \mathbf{p p m}) \delta_{\mathrm{H}}(3 \mathrm{H}, 1,83 ; \mathrm{s}$; H2") $(1 \mathrm{H}, 1.93$; dd : $J=14,4 \mathrm{~Hz}$; H9a); $(1 \mathrm{H}, 2.50$; ddt : $J=14,4,2 \mathrm{~Hz} ; \mathrm{H} 9 \mathrm{~b}) ;(1 \mathrm{H}$, 2.91 ; dd $: J=19.5 ; 5.5 \mathrm{~Hz} ; \mathrm{H} 4 \mathrm{a}) ;(1 \mathrm{H}$, $3.03 ; \mathrm{d} ; J=19.5 \mathrm{~Hz} ; \mathrm{H} 4 \mathrm{~b}) ;(1 \mathrm{H}, 4.59$; brs ; H5); (1H, 4.80 - 4.84 ; m ; H1); (1H, $5,03 ; \mathrm{d} ; J=1.5 \mathrm{~Hz} ; \mathrm{H} 7) ;(1 \mathrm{H}, 5.21 ; \mathrm{dd}$; $J=3,1.5 \mathrm{~Hz} ; \mathrm{H} 8) ;(5 \mathrm{H}, 7.27-7.33 ; \mathrm{m}$; 
H1'-H6'). ${ }^{13} \mathbf{C}-\mathbf{N M R}\left(\mathbf{C D C l}_{\mathbf{3}}, \mathbf{p p m}\right) \delta_{\mathrm{C}}$ 20.6 (C2"), 25.0 (C9), 36.4 (C4), 66.2 (C5), 68.5 (C8), 69.7 (C7), 72.7 (C1), 126.5 (C2'/C6'), 128.3 (C3'/C5'), 128.4 (C4'), 136.6 (C1'), 168.8 (C3), 169.2 (C1"). EI-MS $(70 \mathrm{eV}) \mathrm{m} / \mathrm{z}$ (rel. int.) : 276( $\left.\mathrm{M}^{+}\right)(3 \%), 233(16 \%), 216(10 \%), 145$ (5\%), 128 (3\%), 107 (46\%), 105 (40\%), 91 (20\%), 77 (22\%), 43 (100\%)

Spektra ${ }^{13} \mathrm{C}-\mathrm{NMR}(125 \mathrm{MHz}$

$\mathrm{CDCl}_{3}$ ) 9-deoksigoniopipiron asetat menunjukkan bahwa terdapat 13 sinyal atom karbon yang tidak ekuivalen secara kimia. Pergeseran kimia $\delta_{\mathrm{C}} 126,5 ; 128,3$; 128,4 ; dan 136,6 ppm menunjukkan ciri khas dari suatu benzena monosubstitusi dengan memberikan 4 sinyal yang berbeda dan ini merupakan sinyal dari 6 atom karbon $\mathrm{sp}^{2}$. Pada $\delta_{\mathrm{C}} 126,5 \mathrm{ppm}$ terdapat 2 atom karbon yang ekuivalen secara kimia sehingga 1 sinyal memberi arti 2 atom karbon begitu pula halnya pada $\delta_{\mathrm{C}} 128,3$ ppm terdapat 2 atom karbon yang ekuivalen secara kimia sehingga 1 sinyal memberi makna 2 atom karbon. Sinyal $\delta_{\mathrm{C}}$ 168,8 dan 169,2 ppm menunjukkan dua atom karbon $\mathrm{sp}^{2}$. Kedua sinyal ini merupakan sinyal khas dari suatu ester. Pergeseran kimia antara 66-72 ppm disebabkan atom karbon terikat secara $\mathrm{sp}^{3}$ dengan atom yang bersifat elektronegatif seperti oksigen sehingga pergeseran menuju medan yang lebih lemah ( $\delta$ besar). Berbeda halnya dengan $\delta_{\mathrm{C}}$ 20-36 ppm dimana karbon berikatan secara $\mathrm{sp}^{3}$ dengan atom karbon sehingga berada pada medan yang kuat ( $\delta$ kecil). Dari spektrum ${ }^{13} \mathrm{C}-\mathrm{NMR}$ menunjukkan 15 atom karbon dengan 7 atom karbon $\mathrm{sp}^{3}$ dan 8 atom karbon $\mathrm{sp}^{2}$.

Spektra ${ }^{1} \mathrm{H}-\mathrm{NMR} \quad(500 \mathrm{MHz}$, $\mathrm{CDCl}_{3}$ ) 9-deoksigoniopipiron asetat menunjukkan terdapat 16 proton. Pada $\delta_{\mathrm{H}}$ 7,27-7,33 ppm terdapat spektra multiplet dengan jumlah integrasi sebanyak 5 . Spektra ini membuktikan bahwa terdapat benzena monosubstitusi dengan jumlah proton sebanyak 5. Didukung juga dengan spektra ${ }^{13}$ C-NMR sebelumnya yang menunjukkan terdapat signal khas dari benzena monosubstitusi. Pada $\delta_{\mathrm{H}} 1,83$ ppm terdapat spektra proton singlet dengan integrasi sebanyak 3, menandakan jumlah proton sebanyak 3. Signal ini menunjukkan ciri khas dari suatu gugus metil $\left(\mathrm{CH}_{3}\right)$, dimana proton ini muncul pada medan yang kuat ( $\delta$ yang kecil). Sedangkan $\delta_{H}$ 4,59-5,21 ppm menandakan proton yang berikatan dengan karbon yang terikat secara $\mathrm{sp}^{3}$ dengan atom elektronegatif seperti oksigen sehingga proton tidak terlindungi.

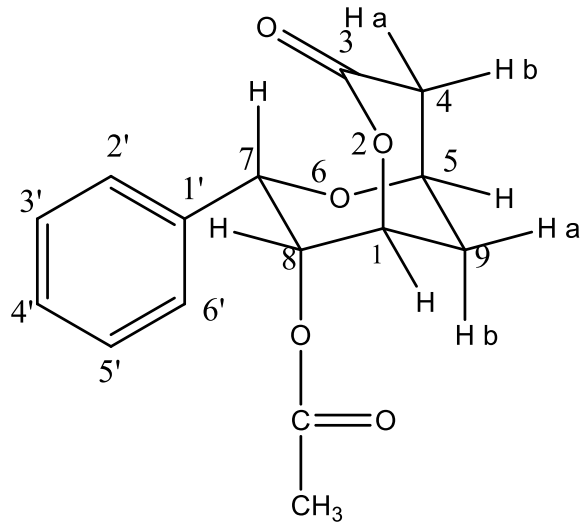

Gambar.1. Senyawa 9-deoksigoniopipiron asetat 
Spektra ${ }^{1} \mathrm{H}-\mathrm{NMR} \quad(500 \mathrm{MHz}$, $\mathrm{CDCl}_{3}$ ) 9-deoksigoniopipiron asetat menunjukkan pada $\delta_{\mathrm{H}} 1,93 \mathrm{ppm}$ dan $\delta_{\mathrm{H}}$ $2,50 \mathrm{ppm}$ terdapat 2 proton yang tidak ekuivalen. Proton $\mathrm{H} 9 \mathrm{a}(1,93 ; d d ; J=14$; $4 \mathrm{~Hz} ; 1 \mathrm{H})$ dan proton $\mathrm{H} 9 \mathrm{~b}(2,50 ; d d t ; J$ $=14 ; 4 ; 2 \mathrm{~Hz} ; 1 \mathrm{H})$. Proton $\mathrm{H} 9 \mathrm{a}$ membentuk spektra doublet of doublet dengan 2 tetapan kopling. Proton H9a saling mengkopling dengan proton $\mathrm{H} 9 \mathrm{~b}$ dengan tetapan kopling yang sama yaitu $14 \mathrm{~Hz}$. Tetapan kopling ini menunjukkan bahwa proton $\mathrm{H} 9 \mathrm{a}$ dan $\mathrm{H} 9 \mathrm{~b}$ terikat melalui penjodohan geminal. Proton H9a juga saling mengkopling dengan H1 dimana memiliki tetapan kopling yang lebih kecil yaitu $4 \mathrm{~Hz}$. Ini menunjukkan bahwa terjadi penjodohan visinal. Hal lain juga mengindikasikan bahwa dalam sistem siklik proton $\mathrm{H} 1$ dengan Proton $\mathrm{H} 9 \mathrm{a}$ dalam posisi ekuatorial-ekuatorial(e-e), ekuatorial-aksial(e-a), atau aksialekuatorial(a-e). Pada konformasi kursi dari sikloheksana nilai ${ }^{3} J_{\mathrm{a}-\mathrm{e}}$ atau ${ }^{3} J_{\mathrm{e}-\mathrm{e}}=2-5$ $\mathrm{Hz}$, sedangkan ${ }^{3} J_{\mathrm{a}-\mathrm{a}}=7-12 \mathrm{~Hz}[6]$. Dari nilai tetapan kopling dapat ditunjukkan bahwa proton $\mathrm{H} 9 \mathrm{a}$ dan $\mathrm{H} 1$ pada konformasi relatif e-e.

Proton $\mathrm{H} 9 \mathrm{~b}$ menunjukkan tipe pola penjodohan yang berbeda dengan membentuk spektra double of doublet triplet dengan 3 tetapan kopling. Proton $\mathrm{H} 9 \mathrm{~b}$ juga saling mengkopling kembali proton H9a dengan tetapan kopling yang sama yaitu $14 \mathrm{~Hz}$. Proton H9b juga mengkopling secara visinal dengan proton H5 dalam posisi konformasi relatif aksialekuatorial dengan tetapan kopling $4 \mathrm{~Hz}$. Sedangkan H9b juga melakukan kopling dengan H4a dengan $J=2 \mathrm{~Hz}$. Korelasi kopling jarah jauh akan terlihat jelas di spektra COSY. Untuk sistem sikloheksana kopling jarak jauh dapat membentuk sistem $\mathrm{W}$, dimana nilai $J=1-3 \mathrm{~Hz}$ [6].
Pada $\delta_{\mathrm{H}} 2,91 \mathrm{ppm}$ dan $\delta_{\mathrm{H}} 3,03$ ppm terdapat 2 proton yang tidak ekuivalen. Proton H4a $(2,91 ; d d ; J=19,5$ ; $5,5 \mathrm{~Hz} ; 1 \mathrm{H})$ dan proton $\mathrm{H} 4 \mathrm{~b}(3,03 ; d ; J$ $=19,5 \mathrm{~Hz} ; 1 \mathrm{H})$. Proton H4a menunjukkan spektra doublet of doublet dengan 2 tetapan kopling. Proton $\mathrm{H} 4 \mathrm{a}$ saling mengkopling dengan proton $\mathrm{H} 4 \mathrm{~b}$ dengan tetapan kopling yang sama yaitu 19,5 Hz. Tetapan kopling ini menunjukkan bahwa proton $\mathrm{H} 4 \mathrm{a}$ dan $\mathrm{H} 4 \mathrm{~b}$ terikat melalui penjodohan geminal. Proton $\mathrm{H} 4 \mathrm{a}$ juga mengalami kopling dengan proton $\mathrm{H} 5$, dimana kedua proton terikat secara visinal dengan $J=5,5 \mathrm{~Hz}$. Sedangkan proton $\mathrm{H} 4 \mathrm{~b}$ menunjukkan spektra doublet dengan $J=$ $19,5 \mathrm{~Hz}$, hal ini menunjukkan bahwa proton $\mathrm{H} 4 \mathrm{~b}$ mengkopling juga proton $\mathrm{H} 4 \mathrm{a}$ dengan tetapan yang sama dan ini membuktikan $\mathrm{H} 4 \mathrm{a}$ dan $\mathrm{H} 4 \mathrm{~b}$ merupakan proton geminal.

Pada $\delta_{\mathrm{H}} \quad 4,59$ ppm dengan integrasi 1 proton $\mathrm{H} 5$ mengalami spektra yang melebar. Sedangkan pada $\delta_{\mathrm{H}} 4,80-$ 4,84 ppm dengan integrasi 1 proton $\mathrm{H} 1$ menunjukkan spektra multiplet. Pada $\delta_{\mathrm{H}}$ 5,03 ppm dengan integrasi 1 proton $\mathrm{H} 7$ menunjukkan spektra doublet dengan $J=$ 1,5 Hz. Tetapan kopling ini menunjukkan bahwa proton $\mathrm{H} 7$ mengkopling proton $\mathrm{H} 8$ terikat secara visinal dengan konformasi relatif ekuatorial-aksial pada sistem sikloheksana. Proton $\mathrm{H} 8$ pada $\delta_{\mathrm{H}} 5,21 \mathrm{ppm}$ dengan integrasi 1 menunjukkan spektra doublet of doublet dengan $J=3 ; 1,5 \mathrm{~Hz}$. Proton H8 mengkopling $\mathrm{H} 1$ dengan nilai tetapan kopling yaitu $3 \mathrm{~Hz}$. Hal ini menunjukkan proton $\mathrm{H} 8$ dan $\mathrm{H} 1$ terikat secara visinal dengan konformasi relatif ekuatorial-ekuatorial. Sedangkan proton H8 mengkopling jarak jauh H9a dengan tetapan kopling 1,5 Hz.

Tabel.1. Data ${ }^{13} \mathrm{C}$-NMR dan ${ }^{1} \mathrm{H}-\mathrm{NMR}$ senyawa 9-deoksigoniopipiron asetat.

\begin{tabular}{ccc}
\hline Posisi & $\boldsymbol{\delta}_{\mathbf{H}}(\mathbf{p p m})$ & $\boldsymbol{\delta}_{\mathbf{C}}(\mathbf{p p m})$ \\
\hline 1 & $4,80-4,84 \mathrm{~m}$ & 72,7 \\
3 & & 168,7 \\
\hline
\end{tabular}




\begin{tabular}{ccc}
\hline $4 \mathrm{a}$ & $2,91 \mathrm{dd}, J=19,5 ; 5,5 \mathrm{~Hz}$ & 36,4 \\
$4 \mathrm{~b}$ & $3,03 \mathrm{~d}, J=19,5 \mathrm{~Hz}$ & 36,4 \\
5 & $4,59 \mathrm{br}, \mathrm{s}$ & 66,2 \\
7 & $5,03 \mathrm{~d}, J=1,5 \mathrm{~Hz}$ & 69,7 \\
8 & $5,21 \mathrm{dd}, J=3 ; 1,5 \mathrm{~Hz}$ & 68,5 \\
$9 \mathrm{a}$ & $1,93 \mathrm{dd}, J=14 ; 4 \mathrm{~Hz}$ & 25,0 \\
$9 \mathrm{~b}$ & $2,50 \mathrm{ddt}, J=14 ; 5 ; 2 \mathrm{~Hz}$ & 25,0 \\
1, & & 136,5 \\
$2,, 6$ & $7,27-7,33 \mathrm{~m}$ & 126,5 \\
$3,, 5$ & $7,27-7,33 \mathrm{~m}$ & 128,3 \\
4 & $7,27-7,33 \mathrm{~m}$ & 128,4 \\
$8-\mathrm{OCOCH}_{3}$ & & 169,2 \\
$8-\mathrm{OCOCH}_{3}$ & $1,83 \mathrm{~s}$ & 20,6 \\
\hline
\end{tabular}

Spektra COSY dari 9deoksigoniopipiron asetat menunjukkan adanya korelasi antara proton $\mathrm{H} 9 \mathrm{a}$ dan $\mathrm{H} 9 \mathrm{~b}$ dengan $J=14 \mathrm{~Hz}$ serta korelasi antara proton $\mathrm{H} 9 \mathrm{a}$ dan $\mathrm{H} 1$ dengan $J=4 \mathrm{~Hz}$. Proton $\mathrm{H} 8$ berkorelasi terhadap proton $\mathrm{H} 1$ dengan $J=3 \mathrm{~Hz}$. Proton $\mathrm{H} 8$ berkorelasi dengan proton $\mathrm{H} 9$ a dengan $J=1,5 \mathrm{~Hz}$. Proton $\mathrm{H} 4 \mathrm{a}$ dan $\mathrm{H} 4 \mathrm{~b}$ saling berkorelasi dengan $J=19,5 \mathrm{~Hz}$. Proton $\mathrm{H} 4 \mathrm{a}$ berkorelasi juga terhadap proton $\mathrm{H} 5$ dengan $J=5,5 \mathrm{~Hz}$ dan dengan proton $\mathrm{H} 9 \mathrm{~b}$ dengan $J=2 \mathrm{~Hz}$. Spektra COSY menunjukkan adanya korelasi jarak jauh dengan 4 ikatan $\left({ }^{4} J\right)$ proton H8 dengan $\mathrm{H} 9 \mathrm{a}$ dan proton $\mathrm{H} 4 \mathrm{a}$ dengan $\mathrm{H} 9 \mathrm{~b}$. Pada sistem bisiklik pola korelasi jarak jauh ini dapat membentuk orientasi W. Senyawa bisiklik pirano-pyran (deoksigoniopipiron) dengan cincin yang sama juga mengalami korelasi jarak jauh dengan orientasi W [6]. Berdasarkan hasil interpretasi ini dapat diprediksi konformasi cincin bisiklik dalam bentuk kursi-kursi. Spektra HMQC 9deoksigoniopipiron asetat menunjukkan adanya korelasi proton pada $\delta_{\mathrm{H}} 2,91 \mathrm{ppm}$ dan 3,03 ppm dengan karbon $\delta_{\mathrm{C}} 36,42$ ppm. Hal ini menunjukkan bahwa proton $\mathrm{H} 4 \mathrm{a}$ dan $\mathrm{H} 4 \mathrm{~b}$ terikat pada atom karbon yang sama (geminal). Pada $\delta_{\mathrm{H}} 1,93 \mathrm{ppm}$ dan 2,50 ppm berkorelasi dengan karbon $\delta_{\mathrm{C}} 25,01 \mathrm{ppm}$. Korelasi ini juga menunjukkan bahwa $\mathrm{H} 9 \mathrm{a}$ dan $\mathrm{H} 9 \mathrm{~b}$ terikat pada atom karbon yang sama (geminal).

Spektra HMBC dari 9deoksigoniopipiron asetat menunjukkan terdapat korelasi antara karbon $\mathrm{C} 3$ dengan proton $\mathrm{H} 4 \mathrm{a}$ dan $\mathrm{H} 4 \mathrm{~b}\left({ }^{2} J_{\mathrm{C}, \mathrm{H}}\right)$. Proton $\mathrm{H} 4 \mathrm{~b}$ juga berkorelasi terhadap C5 $\left({ }^{2} J_{\mathrm{C}, \mathrm{H}}\right)$ dan karbon $\quad \mathrm{C} 9 \quad\left({ }^{3} J_{\mathrm{C}, \mathrm{H}}\right)$. Proton $\mathrm{H} 7$ menunjukkan korelasi terhadap $\mathrm{Cl}^{\prime}$ dan C8 $\left({ }^{2} J_{\mathrm{C}, \mathrm{H}}\right)$, serta $\mathrm{H} 7$ juga berkorelasi terhadap $\mathrm{C} 2$ ' dan $\mathrm{C} 6{ }^{\prime}\left({ }^{3} J_{\mathrm{C}, \mathrm{H}}\right)$. Proton $\mathrm{H} 2$ ' dan $\mathrm{H}^{\prime}$ ' berkorelasi terhadap $\mathrm{C} 7\left({ }^{3} J_{\mathrm{C}, \mathrm{H}}\right)$. Sedangkan proton $\mathrm{H}^{\prime}$ ' dan $\mathrm{H} 6$ ' berkorelasi juga terhadap C8 $\left({ }^{4} J_{\mathrm{C}, \mathrm{H}}\right)$. Proton-proton fenil juga saling berkorelasi dengan karbon-karbon dari fenil dan proton metil dari gugus asetil berkorelasi dengan $\mathrm{C} 1 "\left({ }^{2} J_{\mathrm{C}, \mathrm{H}}\right)$. 


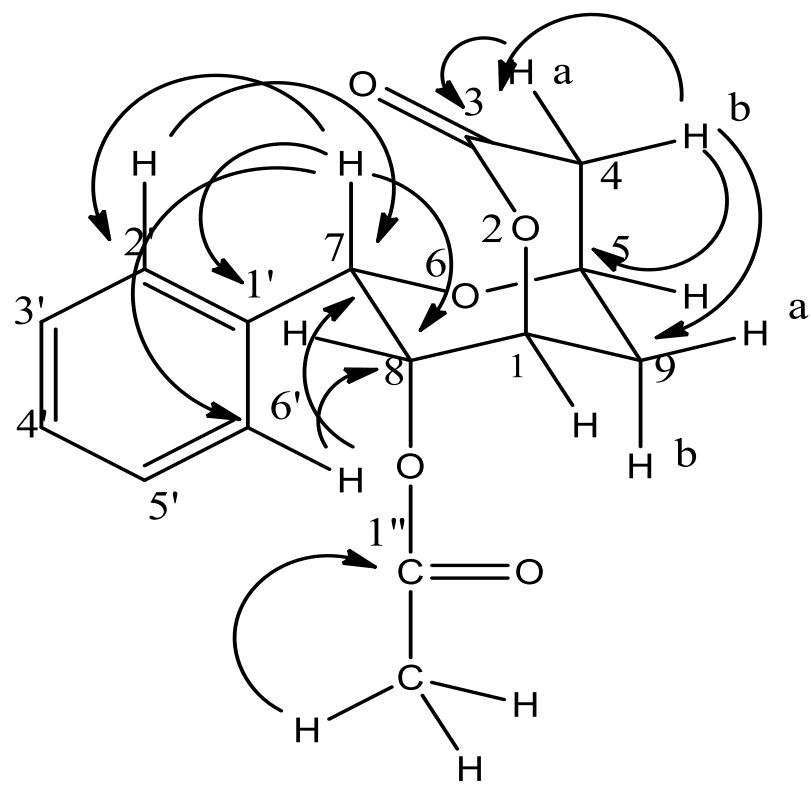

Gambar.2. Korelasi HMBC senyawa 9-deoksigoniopipiron asetat

Senyawa dengan konfigurasi berbeda sebelumnya telah dilaporkan dari Goniothalamus scortechinii [7]. Senyawa 9-deoksigoniopipiron memiliki 4 nama yang berbeda berdasarkan konfigurasi pada karbon kiral dari struktur ini yaitu C1, C5, C7 dan C8. Penentuan konfigurasi atom kiral biasanya dilakukan dengan metode Mosher [8]. Pada tumbuhan Goniothalamus macrophyllus Hook.f. \& Thoms, baru pertama kali dilaporkan keberadaan senyawa 9deoksigoniopipiron asetat dan senyawa ini termasuk golongan stirillakton.

\section{KESIMPULAN}

Telah berhasil diisolasi senyawa 9-deoksigoniopipiron asetat dari daun tendani (Goniothalamus macrophyllus Hook.f. \& Thoms) asal Kalimantan Timur. Senyawa 9-deoksigoniopipiron asetat termasuk di dalam kelompok metabolit sekunder stirillakton.

\section{DAFTAR PUSTAKA}

1. Saunders, R. M. K., and Chalermglin, P., 2008, A Synopsis of Goniothalamus Species (Annonaceae) in Thailand, with Descriptions of Three New Species, Bot. J. of the Linn. Soc., 156 : 1101-1103

2. Phetkul, U, 2009. Chemical Constituents from The Stems of Goniothalamus macrophyllus, Thesis, Prince of Songkla University, Thailand

3. Sam, T. W., Chew, S. Y., Matsjeh, S., Gan, E. K., Razak, D., and Mohamed, A. L., 1987, Goniothalamin oxide: an Embryotoxic Compound from G. macrophyllus (Annonaceous), Tetra. Left., 28 : 2541-2544

4. Abdullah N., Anwar SH., Ideris S., Hasuda T., Hitotsuyanagi Y., Takeya K., Diedrich M., and Choo CY., 2013, Goniolandrene A and B from Goniothalamus macrophyllus.

Fitoterapia, $88:$ : 1-6 
5. Humeirah, S. A. G., Nor Azah, M. A., Mastura, M., Mailina, J., Saiful, J, A.,

6. Muhajir, H., and Puad, A. M., 2010, Chemical Constituents and Antimicrobial Activity of Goniothalamus macrophyllus (Annonaceae) from Pasoh Forest Reserve, Malaysia. Africa. J. of Biotech. 9(34) : 5511-5515

7. Bui, H, T., Vu, T, H., Tran, T, H., Nguyen, X, N., Eun, M, C., Jeong, A, K., Pham, Q, L., Nguyen, M, C., and Young, H, K., 2010, New PyranoPyrone from Goniothalamus tamirensis Enhances the Proliferation and Differentiation of Osteoblastic
MCT3T3-E1 Cells. Chem. Pharm. Bull. 58(4) : 521-525

8. Prawat, Uma., Sawitree, C., Akkarapol, B., Abdul, W, S., and Pittaya, T., 2012, Bioactive Styryllactones, Two New Napthaquinones and One New Styryllactone, and Other Constituents from Goniothalamus scortechinii. Phyto. Lett. 5 : 529-534

9. Yu, H, L., Fang, R, C., Chih, C, L., Chin, C, W., Michael, Y, C., and Yang, C, W., 2004, Digoniodiol, Deoxygoniopypyrone A, and Goniofupyrone A : Three New Styryllactones from Goniothalamus amuyon. Planta Med., 71 : 153-159 